\title{
An example of three dimensional ground model development for earthquake response analysis by using a simple ground modeling system
}

\author{
Y. Tamari ${ }^{\text {i) }}$, Y. Suzuki ${ }^{\text {ii)}}$, Y. Nakagama ${ }^{\text {iii) }}$ and Y. Otsuka ${ }^{\text {iii) }}$
}

\begin{abstract}
i) Manager, Tokyo Electric Power Services, Toyosu Groundsquare 9F 1-7-12 Shinonome Koto-ku Tokyo Japan. ii) Group manager, Tokyo Electric Power Services, Toyosu Groundsquare 9F 1-7-12 Shinonome Koto-ku Tokyo Japan. iii) Member, Tokyo Electric Power Services, Toyosu Groundsquare 9F 1-7-12 Shinonome Koto-ku Tokyo Japan.
\end{abstract}

\begin{abstract}
The geotechnical engineering industry has taken an interest in three dimensional (3D) ground modeling more than before owing to recent prevailing of Construction/Civil Information Modeling (CIM). However, it is said that 3D ground model development, even only creation of 3D geological framework model of subsurface, takes still considerable time and cost due to special technique which requires qualified experts and geological knowledge. Therefore, it is important for practical geotechnical design engineers to find the way to create 3D models efficiently. The authors tried to develop 3D ground model of which dimension is approximately $2.8 \mathrm{~km} \mathrm{x} 1.8 \mathrm{~km}$ with widely spaced borehole logs for conducting earthquake response analysis. We used 3D ground modeling system of 'Geomap3D' (Toyoda and Nishikaichi, 2005) which has been developed as simple ground modeling system. In this report, the outline of developing 3D geological subsurface model is explained as an example of site specific study. Property values of each engineering unit are summarized as well based on literal values. It was found that 3D model could efficiently be developed by using this system in spite of limited number of borehole logs.
\end{abstract}

Keywords: 3D ground model, a simple ground modeling system, earthquake response analysis

\section{INTRODUCTION}

Since the performance based design of geotechnical structures has become the mainstream for seismic design (Boulanger et al. 2017), soil structure interaction (SSI) analysis has been often carried out to evaluate seismic response of structures. Although it is still common to perform SSI analysis in two dimensions (2D) due to simplicity, three dimensional (3D) SSI analysis has been possible to implement because of the recent development of computer technology. In this situation, it is desired in some situation to take 3D geological framework around structures into consideration for numerical model.

On the other hand, the geotechnical engineering industry has begun to take an interest in 3D ground modeling owing to recent prevailing of Construction/Civil Information Modeling (CIM). As part of CIM, detailed specifications of 3D ground model developments are standardized by Japan Geotechnical Consultants Association, and published as guidance (JGCA, 2016). 3D modeling has become possible by less powerful computers and at lower cost ever than before. This is due to development of modeling software tools over the past a few decades. The major software known mainly in Japan are listed as follows; 'GEOLAMA' (Yamane and Sakakibara, 1992),
'CIGMA' (Sakamoto et al., 1993; Sakamoto, 1994), 'SIGMA' (Howard, 2002), 'Geomodel2003' (Yonezawa et al, 2004), 'Geomap3D' (Toyoda and Nishikaichi, 2005), '3D Geomodeller' (Intrepid Geophysics, 2006), 'GSI3D’ (British Geological Survey, 2011).

However, it is said practically that 3D ground model development, even only creation of 3D geological framework model of subsurface, still has problems. It is often the case that field observations are usually very widely spaced, resulting in the lack of sufficient factual data. In this situation, iterative methods involving assessments and progressive refinements by qualified experts are required. These procedures usually add considerable time and cost to creation of 3D models (Kessler et al., 2008). Moreover, modification of 3D model once developed also takes time in some cases. Therefore, it is important for practical geotechnical engineers to find the way to overcome those difficulties.

The authors tried to develop 3D subsurface model of which study area is approximately $2.8 \mathrm{~km} \times 1.8 \mathrm{~km}$ for practical earthquake response analysis of ground. One of simple 3D ground modeling software of 'Geomap3D' (Toyoda and Nishikaichi, 2005, Toyoda et al. 2015) is used. Borehole logs from 'KuniJiban' (Ministry of Land, Infrastructure, Transport and Tourism (MLIT), 
Japan), and pre-existing data in transmission tower foundation design were used. Typical property values for defined engineering units are summarized based on literal values. In this report, we explain the outline of developing 3D ground model as an example of specific site study to show how systematically 3D framework model is created.

\section{BRIEF DESCRIPTION OF SITE}

The site we develop 3D ground model for earthquake response analysis is located at Kofu basin in Yamanashi prefecture, Japan. The site location map is shown in Fig. 1. Kofu basin has a length of about $20 \mathrm{~km}$ in an east-west direction, and $15 \mathrm{~km}$ in a north-south direction. The basin is regarded as structural basin which is surrounded by mountains in three directions. The elevation of its bottom ground surface is about $260 \mathrm{~m}$. Gravel and sandy subsoil of about $40 \mathrm{~m}$ thick exists underlain by sedimentary stratum and tertiary formation. The site is located at the south tip of the basin. Electric transmission line is laid along the river. Four towers are located at the center of study area.

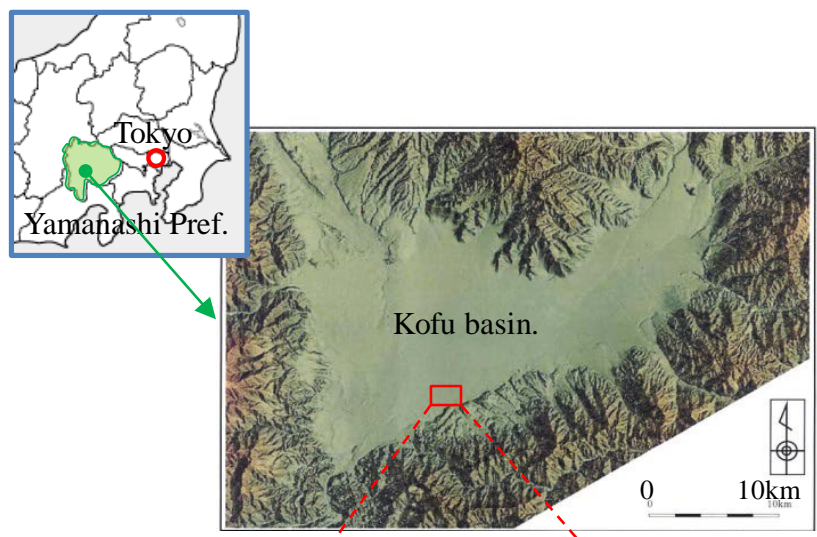

(Yamánashi Pref. Japan, 2003)

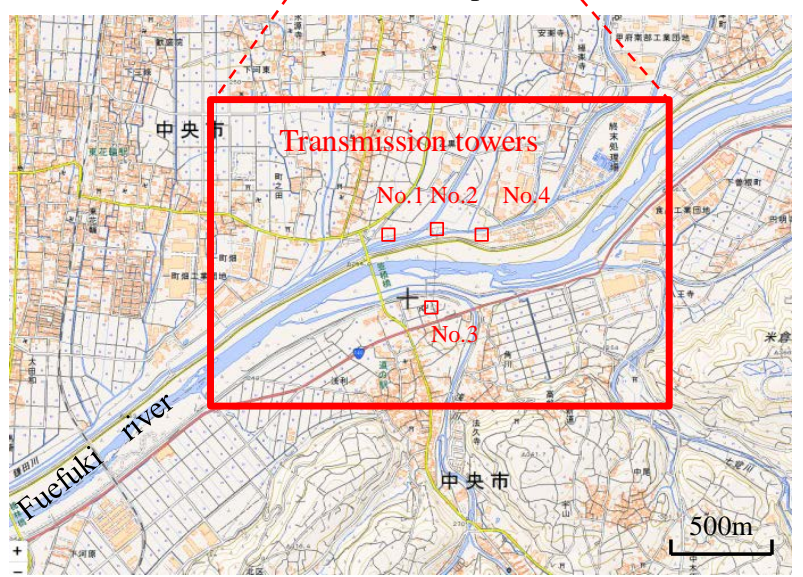

(Electronic map by Geographical Survey Institute, Japan. Study area and location of transmission towers are retouched by authors.)

Fig. 1. The location map of the site

\section{METHODOLOGY OF 3D GEOLOGICAL FRAMEWORK MODEL DEVELOPMENT}

\subsection{Brief expression of 3D ground modeling system used in this study}

We used 3D ground modeling system of 'Geomap3D' (Toyoda and Nishikaichi, 2005, Hasegawa and Nishikaichi, 2005) for developing 3D geological framework model. This modeling system has been developed with support by National Institute of Advanced Industrial Science and Technology, Japan (AIST). The system is designed for geotechnical engineers to develop 3D model in case borehole logs are even very widely spaced, incorporating knowledge of historical geology into the system. Project specific geological data can be used in addition to borehole logs open to public by 'Kunijiban' (MLIT). This system is usually installed and operated on laptop computers, being regarded as a simple and reasonable ground modeling system.

\subsection{Data for geological framework}

Total of 22 borehole logs are used to develop 3D geological framework of this study area. Location of each borehole logs is illustrated in Fig. 2. 10 borehole logs come from 'Kunijiban' (MLIT), other 12 logs are from project-specific investigation by power grid company.

Regarding ground surface elevations, we referred to $5 \mathrm{~m}$ grid elevation data by Geographical Survey Institute, Japan (GSI). Undulation of ground surface by river banks and tributaries is significant around transmission towers. We used detailed elevation data just around transmission towers with precision of about $15 \mathrm{~cm}$ in vertical and horizontal direction. The measurement was separately conducted using aerial photographic survey by authors.

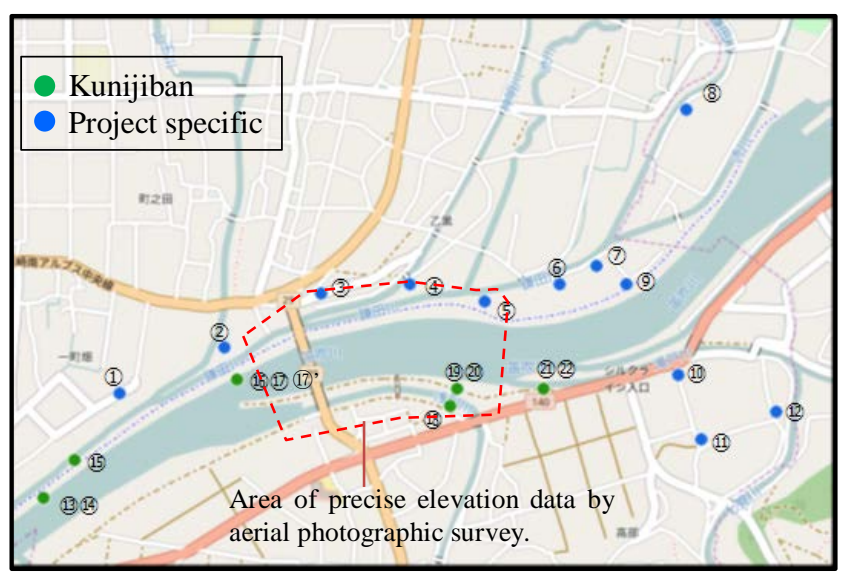

Fig. 2. Location of borehole logs in the study area.

\subsection{Data for soil properties}

Soil properties are specified referring to the public data by NIED (JSHIS, K-net, 2018), and Yamanashi Prefecture (Yamanashi Pref, 2003). Pre-existing data from specific project are referred as well. 


\subsection{Procedure of 3D framework model} development

Procedure to develop 3D framework model is summarized as follows;

a) Unification of geological data

Digitize and store geological data of borehole logs in the data format standardized by AIST, Japan which is in extensible mark-up language XML.

b) Setting of study area

Set an exact area for 3D ground model considering purpose of the study.

c) Location identification of borehole logs

Identify exact location of all borehole logs. Elevation at the top of borehole should be identified as well.

d) Classification of soil strata in borehole logs

Subdivide subsurface ground into several engineering unit on the basis of geological age and soil type, considering key layers if possible.

Select a couple of typical borehole logs as 'index borehole logs'. Regarding only index borehole logs, classify soil strata into engineering units. Then classify all the other soil strata in borehole logs other than index borehole logs. In this procedure, apply Dynamic Waveform Matching (DWM) method (e.g., Toyoda and Shibahara, 2018) in which 'the index of degree of non-similarity, $I_{n s}$ ' is used to evaluate similarity between soil strata. This index is calculated with weighting factor $k$ from such indices as;

i) Similarity of geologic facies : $S_{g f}$ (see values in Table 1) $\left(k_{1}=1.0\right)$

ii) Difference of average standard penetration test (SPT) blow count values : $D_{S P T}\left(k_{2}=\right.$ $0.5)$

iii) Difference of elevation at the center of geological unit : $D_{E L U}\left(k_{3}=0.2\right)$

iv) Difference of ground surface elevation at the borehole : $D_{G L}\left(k_{4}=0.2\right)$

$I_{n s}=S_{g f} \cdot k_{1}+D_{S P T} \times k_{2}+D_{E L U} \times k_{3}+D_{G L} \times k_{4}$

When $I_{n s}<5.0$, the target soil stratum is regarded as identical to the index soil stratum.

\section{e) Identification of erosional unconformity}

Evaluate the possible erosional unconformity in the study area considering geological sequence and the likely geomorphological evolution. Identify key stratum of unconformity in each borehole logs.

f) Calculation of geological boundary between engineering unit by interpolation

Calculate the shape of geological boundary between engineering units considering elevation data points at borehole logs.
Table 1. Matrix for degree of similarity of geologic facies $\left(S_{q f}\right)$

\begin{tabular}{|c|c|c|c|c|c|c|c|c|c|c|}
\hline \multirow{2}{*}{\multicolumn{2}{|c|}{$\begin{array}{l}\text { Soil } \\
\text { description }\end{array}$}} & \multicolumn{9}{|c|}{ Borehole log for comparison } \\
\hline & & G & SL & SM & $\mathrm{S}$ & $\mathrm{Si}$ & $\mathrm{C}$ & $\mathrm{Lm}$ & $\mathrm{Pt}$ & $\mathrm{B}$ \\
\hline \multirow{9}{*}{$\begin{array}{c}\text { Index } \\
\text { borehole } \\
\text { log }\end{array}$} & $\mathrm{G}$ & 0 & 1 & 2 & 4 & 6 & 8 & 16 & 10 & 20 \\
\hline & $\mathrm{SL}$ & 1 & 0 & 1 & 3 & 5 & 7 & 15 & 9 & 19 \\
\hline & SM & 2 & 1 & 0 & 2 & 4 & 6 & 14 & 8 & 18 \\
\hline & S & 4 & 3 & 2 & 0 & 2 & 4 & 12 & 6 & 16 \\
\hline & $\mathrm{Si}$ & 6 & 5 & 4 & 2 & 0 & 3 & 11 & 4 & 14 \\
\hline & $\mathrm{C}$ & 8 & 7 & 6 & 4 & 2 & 0 & 8 & 2 & 12 \\
\hline & Lm & 16 & 15 & 14 & 12 & 11 & 8 & 0 & 6 & 4 \\
\hline & $\mathrm{Pt}$ & 10 & 9 & 8 & 6 & 4 & 2 & 6 & 0 & 10 \\
\hline & $B$ & 20 & 19 & 18 & 16 & 14 & 12 & 4 & 10 & 0 \\
\hline
\end{tabular}

G : Clean Gravels, Gravels with Fines, SL : Coarse sand

SM : Medium sand, Sand, Sandy soil, S : Fine sand, Fine soil

Si : Silt, Cohesive soil, C : Clay, Lm : Loam, Volcanic ash

Pt : Peat, Muck, and other highly organic soils, B : Topsoil, Fill, Bank

The interpolating calculation is based on the method of 'BS-Horizon' (Nonogaki et al, 2008) in which third order B-spline interpolation is used. When erosional unconformity exists, calculation of the shape of the surface is also carried out by interpolation. These routine of interpolation is equipped in the system.

g) Creation of 3D geological framework model

Create 3D model by superimposing each calculated surface of engineering unit.

\section{DEVELOPMENT OF 3D GEOLOGICAL FRAMEWORK MODEL AT THE SITE}

\subsection{Unification of geological data}

The 12 of 22 borehole logs were pre-existing data from project-specific investigation using a medium (paper). First, such information as borehole elevation, water level, elevation of stratum boundary, soil type, description of soils, SPT blow count values and the depth, was converted into electronic formats standardized by AIST, Japan.

\subsection{Setting of study area}

We specified the study area as transmission towers are located at the center of the area. The dimension is approximately $2.8 \mathrm{~km} \times 1.8 \mathrm{~km}$ as illustrated in Fig. 1 . Exact position of the area is from $138 \mathrm{deg}$. 32' 1. '” $^{\prime}$ to 138 deg. 33' 51.75 '” of east longitude in the east-west direction, from 35 deg. 34' 57' to 35 deg. 35' 57.00” of north latitude the north-south direction.

\subsection{Location identification of borehole logs}

The location of all boreholes was specified in longitude and latitude representation. As some borehole data did not show the elevation data at the borehole top, we assumed that the current ground surface elevation as borehole tip elevation. Current elevation was derived from the electronic map provided by GSI, Japan, in which elevation at every 0.2 seconds (about $5 \mathrm{~m}$ ) was provided as digit data.

We compiled all the location and elevation data of borehole log in the system.

\subsection{Classification of soil strata in borehole logs}

In this study area, we subdivided subsurface ground 
into thirteen individual engineering units considering result from pre-existing ground investigation report and SPT blow count values. Table 2 summarizes the classified engineering units.

Table 2. Classified engineering units

\begin{tabular}{|c|c|c|c|c|}
\hline \multirow{13}{*}{$\frac{\text { Geolog }}{\text { Quaternary }}$} & cal age & symbol & color & Log description \\
\hline & \multirow[t]{7}{*}{ Holocene } & Bs & & Topsoil, fill \\
\hline & & As2 & & $\begin{array}{l}\text { Sand, sand mixed with gravel } \\
\end{array}$ \\
\hline & & Ac1 & & $\begin{array}{l}\text { Silt mixed with cray, silt mixed } \\
\text { with gravel }\end{array}$ \\
\hline & & As1 & & Sand, silty sand \\
\hline & & Ac & & Clayey silt, sandy silt \\
\hline & & As & & Fine sand, silty fine sand \\
\hline & & Ag1 & & Gravel, sand \\
\hline & \multirow[t]{5}{*}{ Pleading } & $\mathrm{Dc}$ & & Silt mixed with sand, sandy silt \\
\hline & & Dg1 & & Gravelly soil \\
\hline & & Dgs2 & & $\begin{array}{l}\text { Upper interbedded gravel and } \\
\text { mud }\end{array}$ \\
\hline & & Dgs1 & & $\begin{array}{l}\text { Lower interbedded gravel and } \\
\text { mud }\end{array}$ \\
\hline & & Dgs & & $\begin{array}{l}\text { Lower interbedded sand and } \\
\text { gravel }\end{array}$ \\
\hline Tertiary & & $\mathrm{T}$ & & Bedrock \\
\hline
\end{tabular}

Next, attribution of all soil strata in other borehole logs was defined by DWM method. Two index borehole logs were selected and assigned engineering units as illustrated in Fig. 3(a). Then the index of degree of non-similarity, $I_{n s}$ was calculated between the strata in the other borehole logs. The strata with $I_{n s}$ values less than 5.0 were specified as the same engineering unit. Typical result of classification is depicted in Fig. 3(b). It was noted that this calculation of DWM method is incorporated in the system. This enabled us to complete this work flow very efficiently.

$\mathrm{EL}(\mathrm{m})$

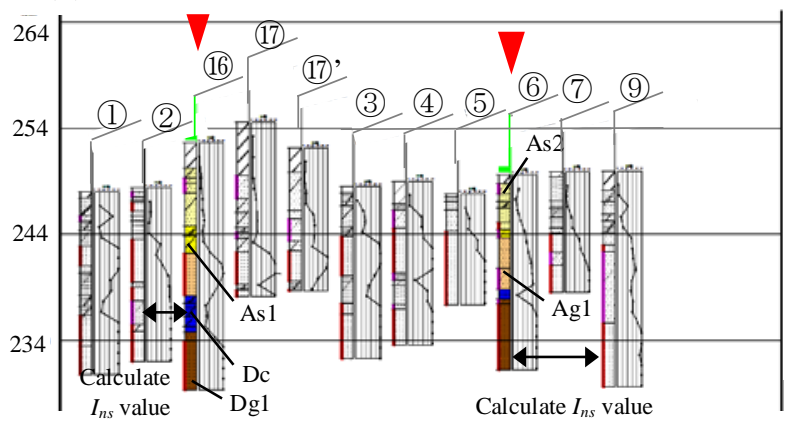

(a) Index borehole logs (colored logs marked by $\nabla$ )

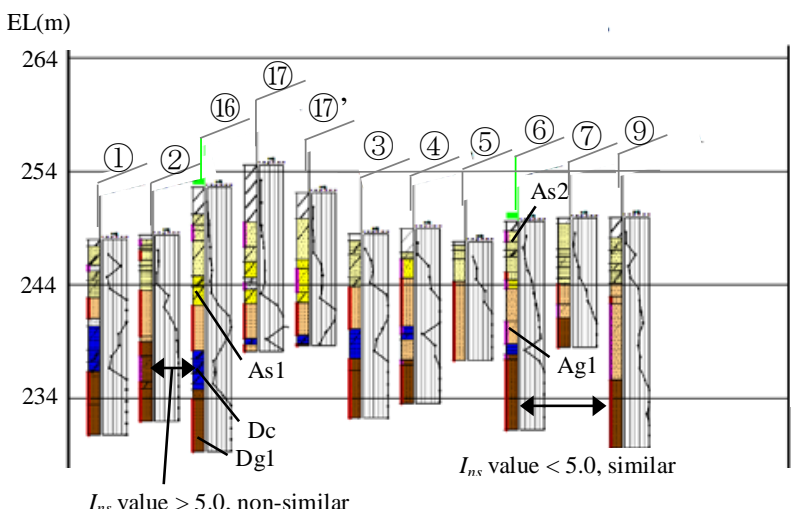

(b) Result of classification by DWM method

Fig. 3. Classification of soil stratum in each borehole log

\subsection{Identification of erosional unconformity}

We considered about presence of eroded surface, which had been ground surface by erosion during certain period of time in the past. Fig. 4 illustrates borehole logs along the river. Gravel unit of 'Ag1' (beige) with SPT blow count values were 30 to 50 is found at about elevation of $240 \mathrm{~m}$ to $245 \mathrm{~m}$ on the whole. However, it was seen that in some borehole logs of $\mathrm{BH}-10,11,12$, the gravel layer of 'Ag1' was not seen at the same elevation (marked by red circle). It was thought from geological sequence that i) after unit of 'Ag1' deposition, gravel was eroded by river, ii) then sandy unit of 'As' and clayey unit 'Ac' was produced. Consequently, we defined erode surface at the top of 'Ag1' (BH-10, 11) and 'Dg1' (BH-12), as the riverbed would be gravelly soil.

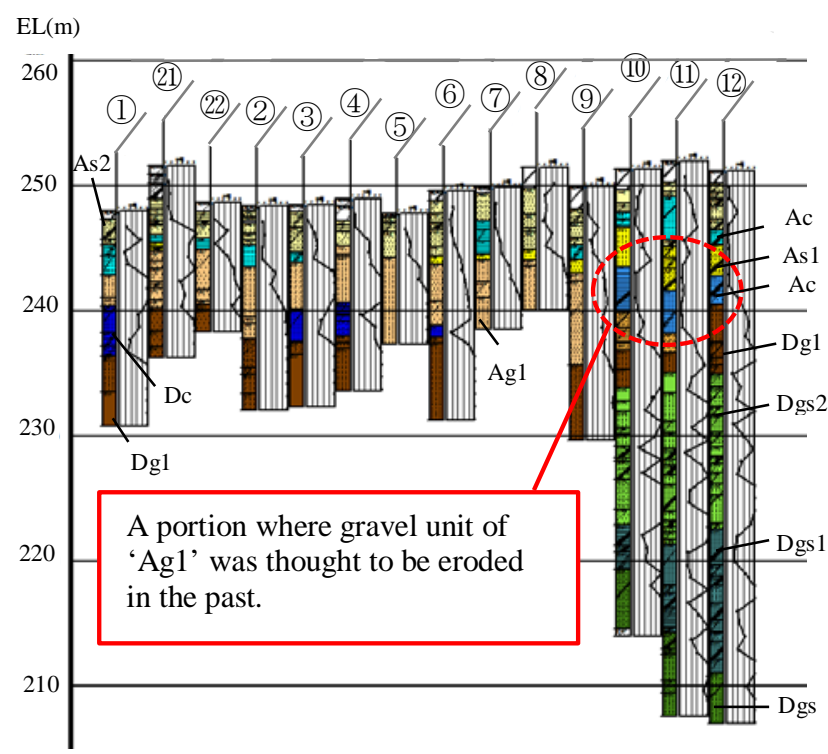

Fig. 4. Possible eroded portion

\subsection{Calculation of boundary between engineering units by interpolation}

Top surface of individual engineering unit listed in Table 2 was calculated by interpolation of elevation data point. The detailed procedure implemented was as follows;

i) Calculated upper surface of engineering unit by interpolation from bedrock to upper unit 'Ag1'. Fig. 5(a) illustrates calculated contour line of unit 'Ag1' as a typical example.

ii) Calculated eroded surface by interpolation of data point at each borehole. Fig. 5(b) depicts calculated contour line of eroded surface. It was seen that the elevation of eroded surface around highlighted portion by red circle was lower than the surface of unit 'Ag1'.

iii) Deleted the eroded portion which was higher elevation from the eroded surface in the model.

iv) Calculated upper surface of engineering units 
which was located upper than eroded surface of 'As', 'Ac', 'As1', 'Ac1', 'As2' and, 'Bs'.

For interpolating calculation, the study area of $2.8 \mathrm{~km} \times 1.8 \mathrm{~km}$ was divided into regularly-spaced meshes of $100 \mathrm{~m} \times 80 \mathrm{~m}$. Hence there were no borehole logs at the edge, the surface was to be calculated by extrapolation. To avoid unnatural shape of surface by calculation, elevation data points were manually added assuming deposited layers as horizontal layer structure.

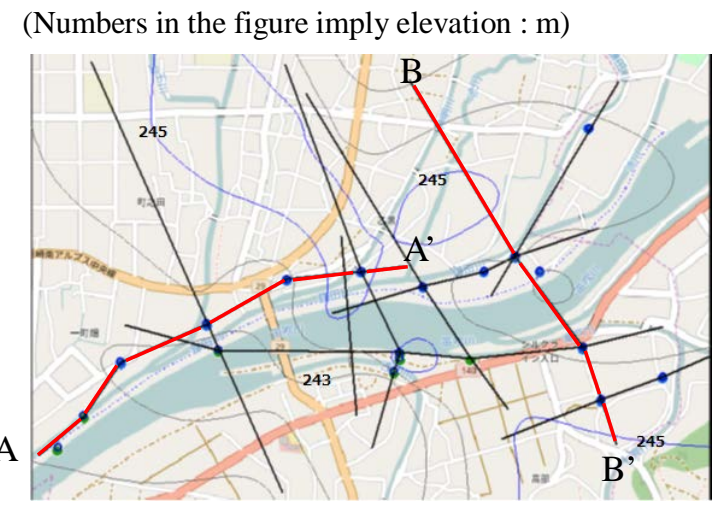

(a) Unit 'Ag1'

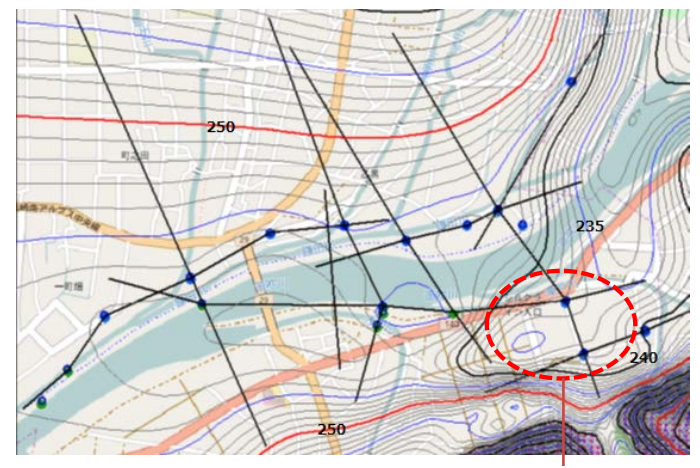

(b) Calculated eroded surface

Elevation 235m-240m

Fig. 5. Counters for upper surface of engineering units

\subsection{Creation of 3D geological framework model}

3D geological framework model was created by superimposing calculated surface. Fig. 6 depicts created 3D model in which the length is exaggerated in vertical direction. Typical view of inside the 3D model at engineering unit 'Ag1' (beige) and 'Dc' (blue) underlain by 'Dg1' (brown) is illustrated in Fig. 7. Eroded portion is seen in unit 'Ag1'. As calculation of boundary and superimposing was incorporated in the system, almost all work could be carried out efficiently.

Synthetic geological cross-section with borehole logs can be easily generated by using the system. Cross-section A-A' in Fig. 5(a) is depicted in Fig. 8(a) and B-B' in Fig. 5(a) is in Fig. 8(b). For a legend, the same color of engineering unit as summarized in Table 2 is applied to the cross-sections.

Cross-section along the line between transmission towers of No.2 and No.3 is illustrated later in Fig. 10 with the same scale in horizontal and vertical direction.
This cross-section is an example which can link with two-dimensional finite element model. The bottom of model is defined at the elevation of zero, and the upper edge inclination of bedrock is assumed to continue linearly from the south to the north direction (right to left in the figure).

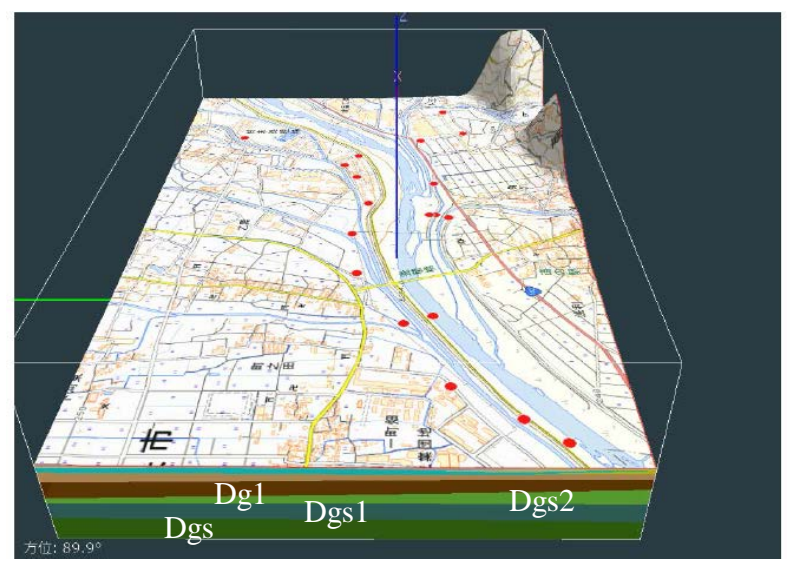

(a) Whole model

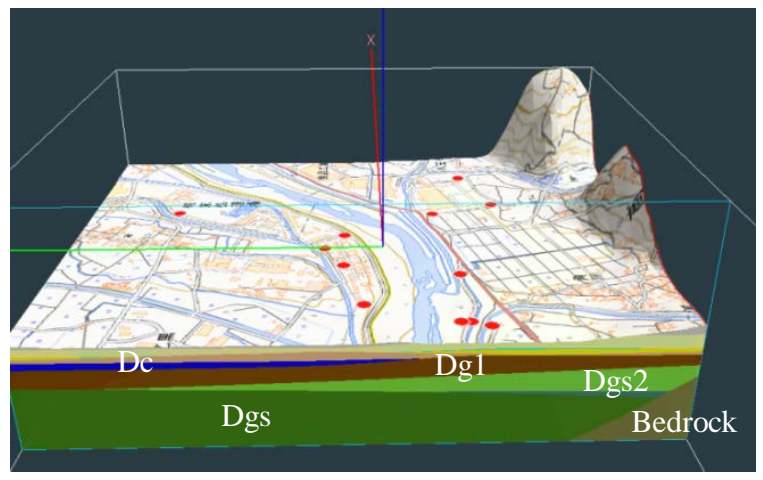

(b) Half model cut at the center of the model

Fig. 6. 3D geological framework model of study area

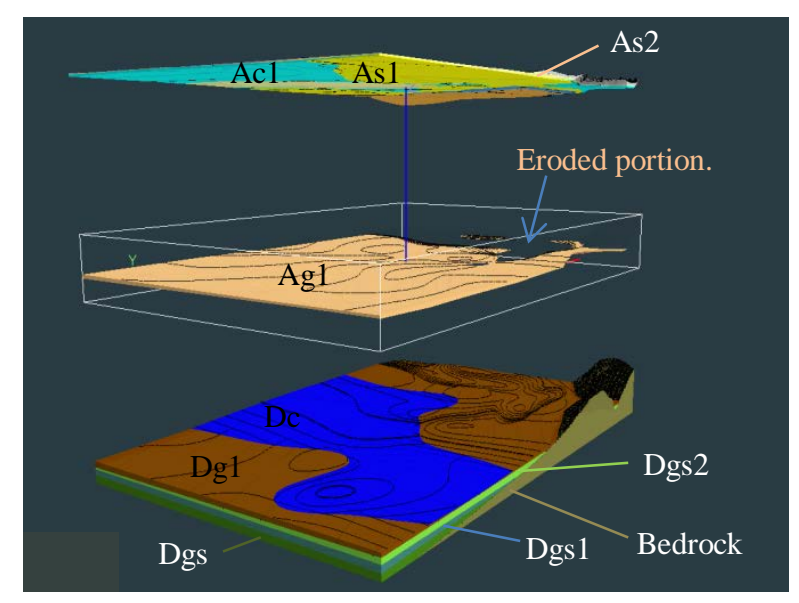

Fig. 7. Distribution of engineering units 


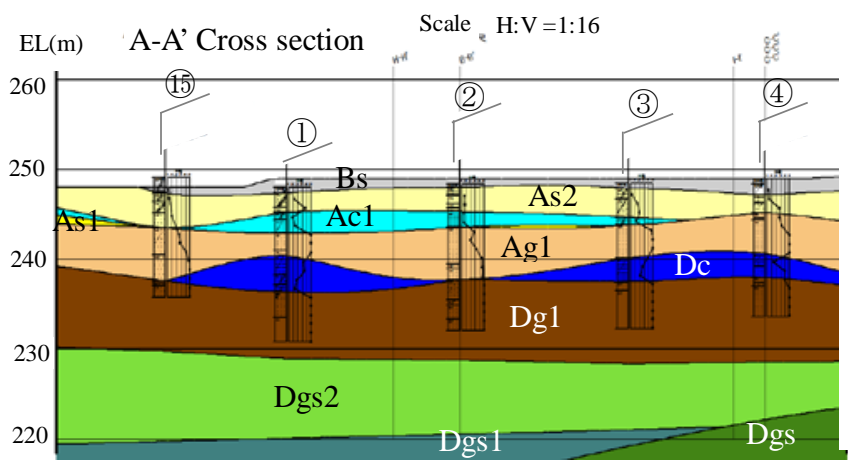

(a) Fence diagram along the river (A-A')

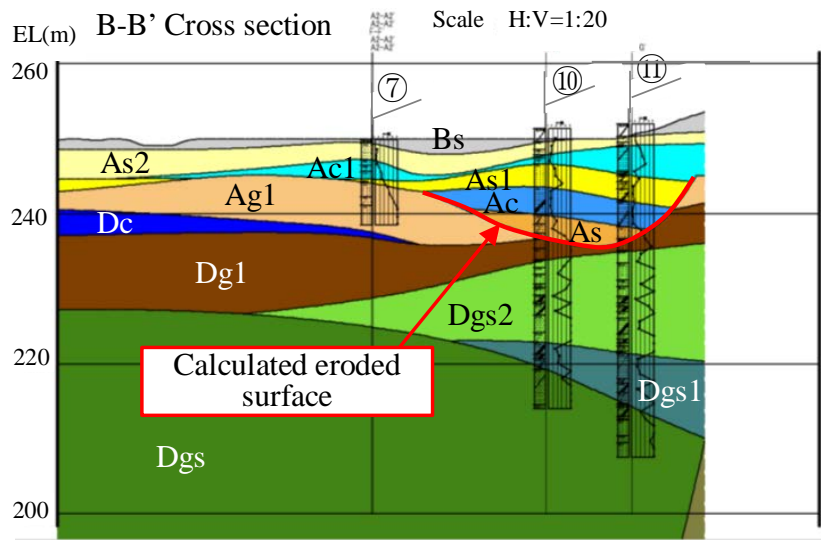

(b) Cross-section perpendicular to the river (B-B')

Fig. 8. Typical synthetic engineering cross-sections

\section{EXAMPLIFICATION OF ATTRIBUTION OF QUANTITATIVE PROPERTIES TO EACH UNIT}

\subsection{Overview}

Hence the major purpose of creation of 3D geological model is implementation of earthquake response analysis of ground, it is necessary to assign a set of single typical value and typical variability for the dynamic properties. Those are usually evaluated based on in-situ or laboratory test results from each engineering unit. However in this study area, geotechnical factual data are very widely spaced and number of test for mechanical properties are not enough to quantitatively evaluate property values and variations. Therefore in this study, a single property value is specified as typical value and attributes to each engineering unit in the model as simplest way. Property values of published geotechnical data is also used (e.g. JSHIS by NIED, 2018, Yamanashi Pref, 2003). Liquefaction characteristic is assessed for such engineering units as alluvium sandy and gravelly strata which in general have liquefaction susceptibility. Property values are arranged for dynamic effective stress analysis program 'FLIP ROSE' (Iai, 2005) which is often used in geotechnical engineering project in Japan.

\subsection{Attribution of quantitative properties}

Average shear wave velocity with depth of $30 \mathrm{~m}$ (Vs30) is reported to change in this study area by NIED, Japan (JSHIS, 2018). Fig. 9 illustrates horizontal distribution of Vs30. It shows that Vs30 value around No.3 transmission tower (yellow) is larger than that of other portion of the study area (orange) including No.2 tower. The reason why is considered that this portion of the land (yellow) is regarded as alluvial fan created by a small river from the south. On the other hand, almost all other part is regarded as marshy land in the rear. We subdivided engineering unit into two to assign different shear wave velocity except for bedrock and unit 'Dgs'.

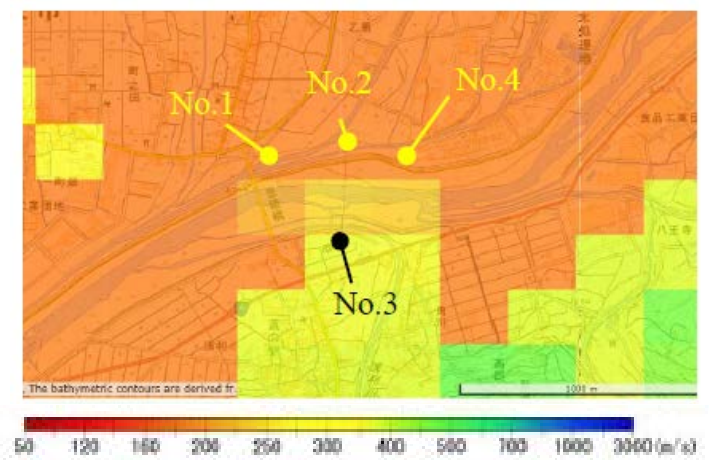

Fig. 9. Distribution of Vs30 values in the study area (JSHIS, 2018)

Elastic wave velocity for each unit in study area was specified following procedure;

Subsurface : Vs30 value is adjusted as Vs $=200 \mathrm{~m} / \mathrm{s}$ at the area of marshy land in the rear, Vs $30=300 \mathrm{~m} / \mathrm{s}$ at alluvial fan. Confining stress dependency of soil is roughly considered from the top engineering unit to the bottom.

Bedrock and diluvium gravel 'Dgs': It is reported by deep ground investigation (Yamanashi prefecture, 2003) that shear wave velocity is Vs $=420 \mathrm{~m} / \mathrm{s} \pm 40 \mathrm{~m} / \mathrm{s}$ at top velocity layer, $V s=730 \mathrm{~m} / \mathrm{s} \pm 60 \mathrm{~m} / \mathrm{s}$ at the second layer. The velocity boundary is located at the depth of about $40 \mathrm{~m}$. Considering the existing reports, we specify shear wave velocity of unit 'Dgs' (diluvium gravel strata) as $V s=400 \mathrm{~m} / \mathrm{s}$, bedrock as $\mathrm{Vs}=700 \mathrm{~m} / \mathrm{s}$.

Such property values as unit weight of soil, internal friction angle, the maximum damping ratio are specified from existing study which is carried out on this site (Tamari et al., 2017) . Cyclic stress ratio of liquefaction characteristics is assessed by estimated SPT value and fine content by grain size analysis based on simple estimate formula in Specifications for Highway Bridges (Japan road association, 2014). Phase transformation angle of sand is determined as 28 degrees (Morita et al., 1997). Property values of individual engineering unit are summarized in Table 3 for the area of marshy land in the rear, and Table 4 for alluvial fan. The locations of tower No.2 and No.3 are represented for the calculation of thickness of each engineering unit $H(\mathrm{~m})$. 


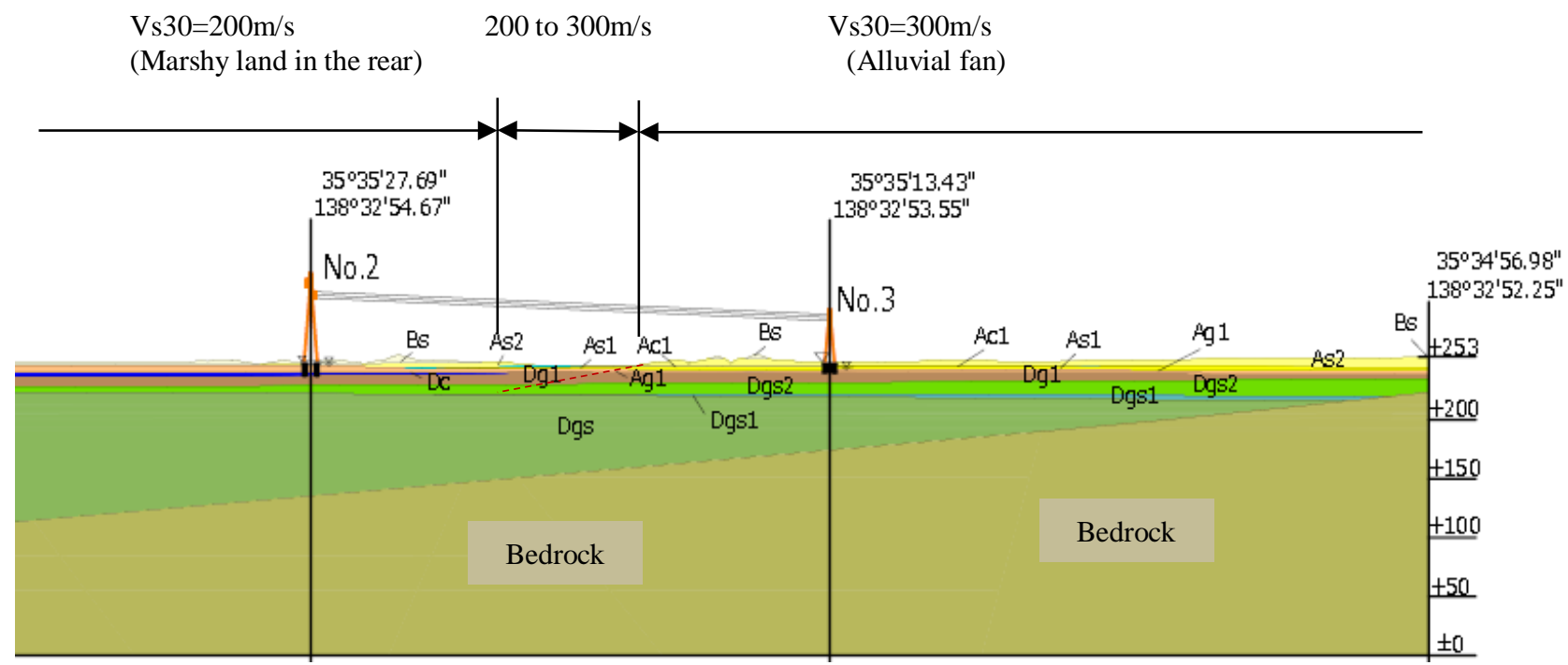

Fig. 10. Cross-section along the line between transmission towers of No.2 and No.3.

Table 3. Parameters forengineering unit (Marsh land in the rear, Vs30=200m/s)

\begin{tabular}{|c|c|c|c|c|c|c|c|c|c|c|}
\hline Layer & $\begin{array}{c}\mathrm{H}(\mathrm{No} .2) \\
(\mathrm{m})\end{array}$ & $\begin{array}{c}\rho \\
\left(\mathrm{t} / \mathrm{m}^{3}\right) \\
\end{array}$ & $\begin{array}{c}\mathrm{V}_{\mathrm{s}} \\
(\mathrm{m} / \mathrm{s})\end{array}$ & $\begin{array}{c}\mathrm{G}_{\mathrm{ma}} \\
(\mathrm{kPa})\end{array}$ & $\begin{array}{c}-\sigma_{\mathrm{ma}}(2 \mathrm{D}) \\
(\mathrm{kPa})\end{array}$ & $\begin{array}{c}-\sigma_{\text {ma }}(3 \mathrm{D}) \\
(\mathrm{kPa})\end{array}$ & $\begin{array}{c}\phi_{\mathrm{f}} \\
(\mathrm{deg})\end{array}$ & $\mathrm{h}_{\max }$ & $\begin{array}{c}\phi_{\mathrm{p}} \\
\text { (deg) }\end{array}$ & $\begin{array}{c}\text { Cyc.Str.Ratio } \\
\text { DA }=5.0 \%\end{array}$ \\
\hline B & 1.40 & 1.6 & 120 & 23040 & 15.1 & 13.4 & 39.0 & 0.24 & - & - \\
\hline B & 1.17 & 1.6 & 120 & 23040 & 15.1 & 13.4 & 39.0 & 0.24 & 28.0 & 0.188 \\
\hline As2 & 2.17 & 1.8 & 150 & 40500 & 36.6 & 32.5 & 43.9 & 0.24 & 28.0 & 0.239 \\
\hline Ag1 & 4.37 & 2.0 & 180 & 64800 & 59.0 & 52.5 & 43.9 & 0.24 & 28.0 & 0.255 \\
\hline Dc & 2.64 & 1.8 & 180 & 58320 & 82.8 & 73.6 & $0.0^{* 1}$ & 0.20 & - & - \\
\hline Dg1 & 9.47 & 2.1 & 200 & 84000 & 128.9 & 114.6 & 43.9 & 0.24 & - & - \\
\hline Dgs2 & 6.55 & 2.1 & 260 & 141960 & 193.6 & 172.1 & 43.9 & 0.24 & - & - \\
\hline Dgs & 86.74 & 2.1 & 400 & 336000 & 503.2 & 447.3 & 43.9 & 0.24 & - & - \\
\hline Bedrock & 135.32 & 2.1 & 700 & - & - & - & - & - & - & - \\
\hline
\end{tabular}

Table 4. Parameters for engineering unit (Alluvial fan, Vs30=300m/s)

\begin{tabular}{|c|c|c|c|c|c|c|c|c|c|c|}
\hline Layer & $\begin{array}{c}\text { H (No.3) } \\
(\mathrm{m})\end{array}$ & $\begin{array}{c}\rho \\
\left(\mathrm{t} / \mathrm{m}^{3}\right) \\
\end{array}$ & $\begin{array}{c}\mathrm{V}_{\mathrm{s}} \\
(\mathrm{m} / \mathrm{s})\end{array}$ & $\begin{array}{c}\mathrm{G}_{\mathrm{ma}} \\
(\mathrm{kPa})\end{array}$ & $\begin{array}{c}-\sigma_{\text {ma }}(2 \mathrm{D}) \\
(\mathrm{kPa})\end{array}$ & $\begin{array}{c}-\sigma_{\mathrm{ma}}{ }^{\prime}(3 \mathrm{D}) \\
(\mathrm{kPa})\end{array}$ & $\begin{array}{c}\phi_{\mathrm{f}} \\
(\mathrm{deg})\end{array}$ & $\mathrm{h}_{\max }$ & $\begin{array}{c}\phi_{\mathrm{p}} \\
\text { (deg) }\end{array}$ & $\begin{array}{c}\text { Cyc.Str.Ratio } \\
\text { DA }=5.0 \%\end{array}$ \\
\hline As2 & 3.61 & 1.8 & 200 & 72000 & 36.6 & 32.5 & 43.9 & 0.24 & - & - \\
\hline As1 & 3.72 & 1.9 & 250 & 118750 & 60.2 & 53.5 & 40.0 & 0.24 & - & - \\
\hline Ag1 & 1.07 & 2.0 & 250 & 125000 & 59.0 & 52.5 & 43.9 & 0.24 & - & - \\
\hline Dg1 & 9.50 & 2.1 & 300 & 189000 & 128.9 & 114.6 & 43.9 & 0.24 & - & - \\
\hline Dgs2 & 10.33 & 2.1 & 350 & 257250 & 193.6 & 172.1 & 43.9 & 0.24 & - & - \\
\hline Dgs1 & 1.81 & 2.1 & 350 & 257250 & 193.6 & 172.1 & 43.9 & 0.24 & - & - \\
\hline Dgs & 44.99 & 2.1 & 400 & 336000 & 503.2 & 447.3 & 43.9 & 0.24 & - & - \\
\hline Bedrock & 135.32 & 2.1 & 700 & - & - & - & - & - & - & - \\
\hline
\end{tabular}

$H$ : layer thickness; $\rho$ : density; $V_{s}$ :shear wave velocity; $G_{m a}$ : elastic shear modulus at a confining pressure of $\left(-\sigma_{m a}\right.$ ');

- $\sigma_{m a}$ ': reference confining pressure; $\phi_{f}$ :shear resistance angle; and $\phi_{p}$ :phase transformation angle,

$\sigma_{m a}(2 \mathrm{D})=\sigma_{v}{ }^{\prime} \cdot(1+K o) / 2, \quad \sigma_{m a}{ }^{\prime}(3 \mathrm{D})=\sigma_{v}{ }^{\prime} \cdot(1+2 K o) / 3, K o$ : earth pressure at rest $(=0.5), \quad \sigma_{v}^{\prime}:$ effective vertical pressure at the center depth of soil unit.

\section{CONCLUSIONS}

3D geological model was created as one of site specific modeling studies. The software of Geomap3D was used which was the one of Japanese domestic 3D modeling software tool, using total of 22 borehole logs from public and site specific project for study area of $2.8 \mathrm{~km} \times 1.8 \mathrm{~km}$. Major conclusion is listed as follows;

i) It was found that two methods incorporated in the system enabled us to create 3D geological framework model efficiently. The one is 'DWM method' for classification of soil strata in boreholes, the other is 'BS-Horizon' for calculation of boundaries between engineering units.

ii) The identification of erosional unconformity was necessary when the soil deposit was not continuous to horizontal direction. Some geological knowledge and consideration were needed in this procedure.

iii) As the simplest approach to attribution of created 3D framework model, a set of typical property values for nonlinear earthquake response analysis was 
summarized referring to public data and literal values.

As was pointed out at the beginning of this paper, one of problems in creating 3D model with widely spaced borehole logs was iterative procedure which took considerable time and cost. However, it seemed that the problem had been overcome using procedure explained in this study. The software of Geomap3D used in this study may be one of the excellent systems to develop 3D model. But other modeling software has also been used and may be better in some situations.

We are going to carry out earthquake response analysis to examine seismic ground behavior on this site using developed 3D model in the near future.

\section{ACKNOWLEDGEMENTS}

The authors express their gratitude to TEPCO Power Grid, Incorporated for providing authors a number of borehole logs at transmission tower foundations. Also authors would like to thank President Mamoru Toyoda from GSI Corporation for his valuable advices and support.

\section{REFERENCES}

1) Boulanger, R. W., Wijewickreme, D. (2017). PBD-III Vancouver, Proc., $3^{\text {rd }}$ Intl. Conf. on Performance-based Design in Earthquake Geotech. Eng., Vancouver, BC, Canada.

2) British Geological Survey (2011) : GSI 3D 2011, Software manual and methodology, Open Report OR/11/020, www.gsi3d.org.uk.

3) Cho, I., Nishikaichi, K., Yanagisawa, Y., Hasegawa, I., and Kuwahara, Y. (2006) : Modeling of Three-Dimensional Geological Structure with Constraints of Geotectonic History: Application to a Seismic Gap Region South of the 2004 Mid Niigata earthquake, Journal of JAEE, 6(4), 74-93. (in Japanese)

4) Geographical Survey Institute, Japan (2018): Electronic topographic map , https://maps.gsi.go.jp.

5) Hasegawa, I., Nishikaichi, K. (2005) : Development of three dimensional geological framework model using Geomap3D - Examplification on Tsukuba area and chuetsu epicentral are in Japan -, Geoinformatics, .16(2), 76-77. (in Japanese)

6) Howard A. (2002): Capturing digital data in the field -The British Geological Survey's SIGMA Project: Digital field data capture in a corporate context, Proc. Capturing Digital Data in the Field Workshop.

7) Iai, S., Matsunaga, Y., Kameoka, T. (1992) : Strain Space Plasticity Model for Cyclic Mobility, Soils and Foundations, 32(2): 1-15.

8) Intrepid Geophysics (2006): 3D GeoModeller Reference Manual. BRFM and Desmond FitzGerald \& Associates Pty. Ltd, 67.

9) Japan Geotechnical Consultants Association (2016): Guidance of development of 3D geological model. (in Japanese)

10) Japan Ministry of Transport (2015): Kunijiban, http://www.kunijiban.pwri.go.jp/jp/index.html.

11) Japan road association (2014) : Specifications for Highway Bridges.(in Japanese)

12) Kessler, H., Turner, A.K., Culshaw, M.G., Royse, K.R. (2008) : Unlocking the potential of digital 3D geological subsurface models for geotechnical engineers, European econference of the International Association for Engineering geology, Madrid, Spain, 15-20, Sept 2008.

13) Morita T., Iai S., Liu H., Ichii K., Sato Y. (1997). Simplified Method to Determine Parameter of FLIP, Technical Note of the Port and Harbour Research Institute, Ministry of Transport, Japan. (in Japanese)

14) National Research Institute for Earth Science and Disaster Prevention (NIED). "Japan Seismic Hazard Information Station (J-SHIS)”. (2016). (http://www.j-shis.bosai.go.jp/).

15) National Research Institute for Earth Science and Disaster Prevention (NIED). "K-NET WWW service”, Japan (http://www.k-net.bosai.go.jp/).

16) Nonogaki, S., Matsumoto, S. and Shiono, K. (2008): Optimal Determination of Geologic Boundary Surface Using Cubic B-Spline, Geoinformatics, 19(2), 61-77.

17) Sakamoto M., Shiono K., Masumoto S., and Wadatsumi K.(1993): A computerized geologic mapping system based on logical models of geologic structures, Nonrenewable Resources, 2, 2, 140-147.

18) Toyoda, M., Kojima, Y. and Sano, A. (2015) : Development of a web-based geological model in the Sapporo area with a system for utilizing geological information -Application of Dynamic Waveform Matching to correlate boring cores-, Geoinformatics, .26(2), 68-69. (in Japanese)

19) Toyoda, M. and Nishikaichi, K. (2005): A system introduction of Geomap3D, Geoinformatics, 16(2), 146-147. (in Japanese)

20) Toyoda, M. and Shibahara, M. (2018): On the Automation of Stratum Assignment and Geological Modeling with a Large Amount of Borehole Data, Proc. of $29^{\text {th }}$ national conf. JSGI, 43-44. (in Japanese)

21) Yamanashi Prefecture, Japan. (2003). Survey of Deep Subsurface Structure Beneath Kofu basin. (in Japanese)

22) Yamane, H., Sakakibara, T. (1992): 'GEO-RAMA ver.3.0' 3D geological analysis system, Poster session in $3^{\text {rd }}$ National Conf. Japan Society of Geoinformatics.

23) Yonezawa, G., Masumoto, S., Nemoto, T., Sakamoto, M., Shiono, K. (2004): Visualization of Geologic Boundaries Based on Generalized Geologic Function, Geoinformatics, 15(4), 193-206. 